\title{
Successful ERCP in a Roux-en-Y gastric bypass patient, performed via a small remnant of gastro- gastric communication
}

Endoscopic retrograde cholangiopancreatography (ERCP) can be challenging in patients after Roux-en-Y gastric bypass surgery. We present a case of such a patient with choledocholithiasis who underwent successful ERCP though a remnant of gastrogastric communication.

A 57-year-old female after successful Roux-en-Y-gastric bypass presented with symptomatic choledocholithiasis. ERCP with a pediatric colonoscope was unsuccessful because of the long Roux limb. On the second ERCP attempt with a balloonassisted enteroscope, we discovered a small opening in the gastric pouch $(\bullet$ Fig. 1a).

With a standard gastroscope (Olympus GIF-H180; Olympus, Center Valley, USA), we passed through the opening into distal stomach, proving it was a remnant connection between the gastric pouch and defunctionalized stomach ( $\bullet$ Fig. 1 b, c). A side-viewing duodenoscope (Olympus TJF-160) was then passed through this communication without further dilatation. Subsequently, a standard biliary sphincterotomy and stone extraction were performed ( Figs. 2 and $\mathbf{3}$ ).

With increased lithogenicity induced by rapid weight loss in post-gastric-bypass patients, cholelithiasis occurs in $38 \%$ of patients within 6 months, and $41 \%$ of these patients develop symptoms [1]. No standardized prophylactic management modality for this patient group has been established thus far [1,2].

In the case of bile duct stones, added complexity from altered anatomy requires utilization of a pediatric colonoscope or balloon-assisted enteroscope [3] during ERCP or passage of the endoscope through a surgical or radiologically placed gastrostomy as previously reported $[4,5]$ for the clearance of the bile duct.

Natural access to the major papilla through gastrogastric communication allowed a significant reduction of the procedure time, effort, and risks by avoiding the balloon-assisted enteroscopy or gastrostomyor enterostomy-access assisted ERCP. This case illustrates that an endoscopist should always seek such an opening in the gastric pouch; research and development into securing a small access route such as through
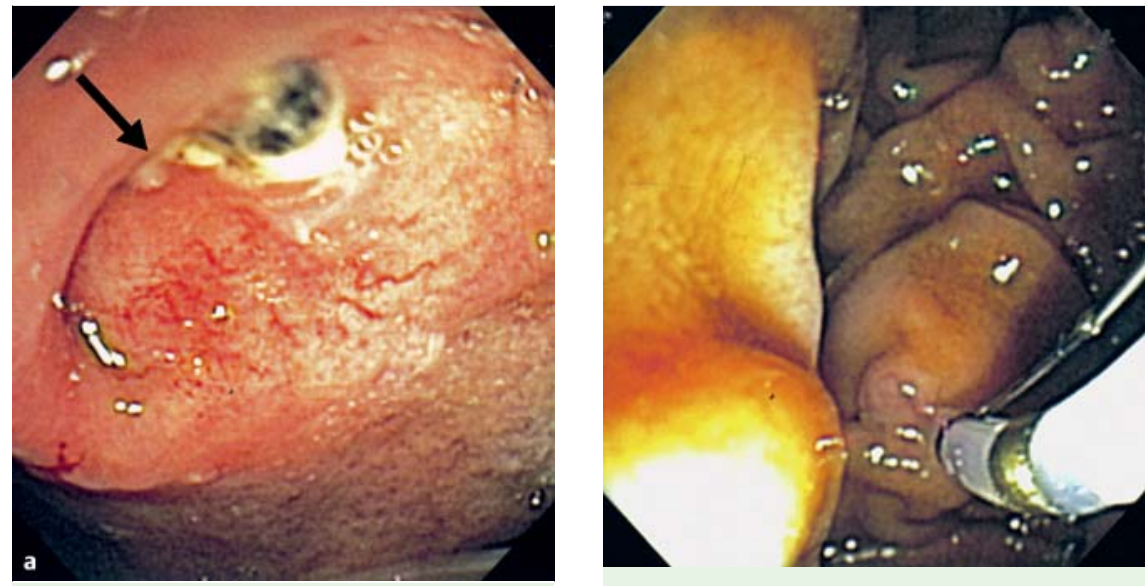

Fig. 2 Standard access to major papilla with a
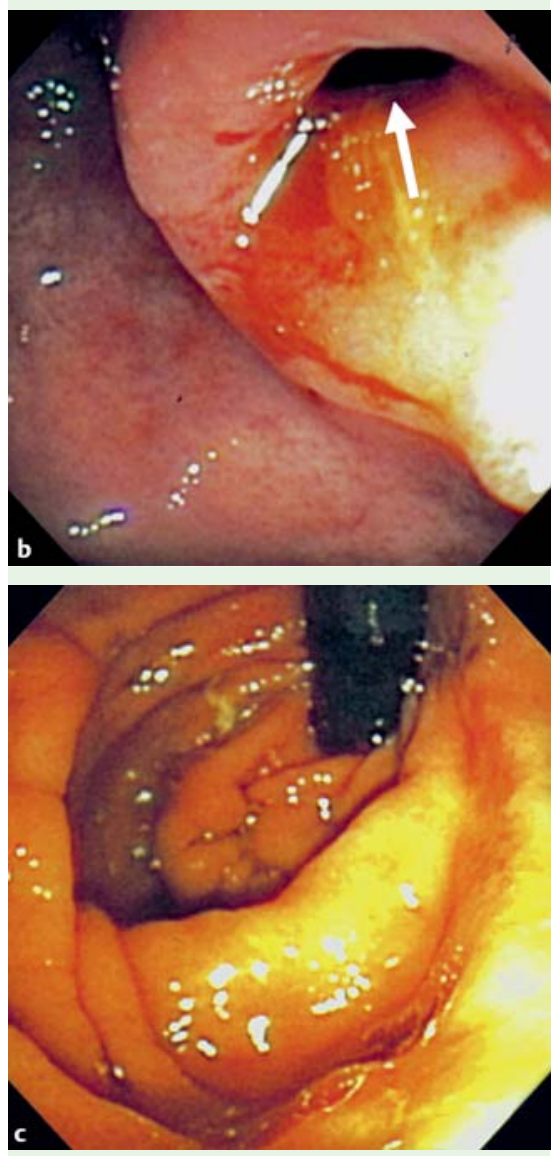

Fig. 1 Gastrogastric communication a before and $\mathbf{b}$ after the passage of a standard gastroscope. c Defunctionalized stomach (retroflexed view) as seen after traversing the gastrogastric communication.

placement of a (temporary or permanent) removable plug or tubing or port into the defunctionalized stomach at the time of sphincterotome.
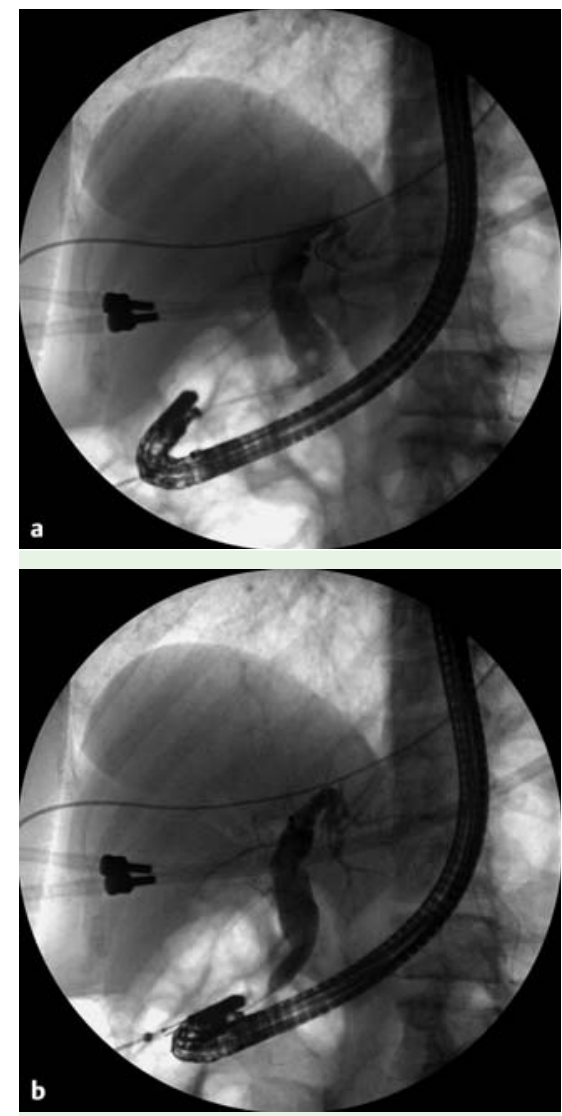

Fig. 3 a Bile duct with multiple stones. b Successful clearing of bile duct.

initial surgery could be considered to help manage the late biliary complication in this surgical subset. 


\section{Endoscopy_UCTN_Code_TTT_1AR_2AK}

\section{Competing interests: None}

\section{A. Madan, S. Urayama}

Division of Gastroenterology and Hepatology, Department of Internal Medicine, University of California Davis Medical Center, Sacramento, California, USA

\section{References}

1 Shiffman ML, Sugerman HJ, Kellum JM et al. Gallstone formation after rapid weight loss: a prospective study in patients undergoing gastric bypass surgery for treatment of morbid obesity. Am J Gastroenterol 1991; 86: 1000-1005

2 Miller K, Hell E, Lang B et al. Gallstone formation prophylaxis after gastric restrictive procedure for weight loss - a randomized double-blind placebo controlled trial. Ann Surg 2003; 238: 697-702

3 Sato H, Tamada K, Kita H et al. Application of double-balloon endoscopy for afferent limb lesions of Roux-en-Y surgical anastomosis. Gastrointest Endosc 2005; 61: AB238

4 Baron TH, Vickers SM. Surgical gastrostomy placement as access for diagnostic and therapeutic ERCP. Gastrointest Endosc 1998; 48: 640-641

5 Baron T. Double-balloon enteroscopy to facilitate retrograde PEG placement as access for therapeutic ERCP in patients with longlimb gastric bypass. Gastrointest Endosc 2006; 64: $973-974$
Bibliography

DOI $10.1055 / \mathrm{s}-0030-1256038$

Endoscopy 2011; 43: E73 -E74

(c) Georg Thieme Verlag KG Stuttgart · New York . ISSN 0013-726X

\section{Corresponding author}

\section{Shiro Urayama, MD}

Division of Gastroenterology and Hepatology University of California, Davis

4150 V Street, PSSB Suite 3500

Sacramento

California 95817

USA

Fax: +1-916-734-7908

surayama@ucdavis.edu 